\title{
STUDY ON THE PATTERN OF UNNATURAL DEATHS OF WOMEN BROUGHT FOR MEDICO-LEGAL AUTOPSY
}

\author{
Kitulwatte I.D.G., Edirisinghe P.A.S., Pratheepa Mendis H.K.N.L., Pavithra. R. Wijesinghe, \\ Anton Fernando \& Rishani M. Abeyrathne A.A.
}

Department of Forensic Medicine, Faculty of Medicine, University of Kelaniya, Sri Lanka

\begin{abstract}
Introduction

An unnatural death is an intentional or unintentional death due to external causes. This can often be violent, mutilating or destructive. When the unnatural death involves a female, it shatters the lives of the survivors or the family. Traumatic injuries among females remain under-reported globally and studies on this area are scarce. We planned a retrospective descriptive study to find the epidemiologic patterns of traumarelated mortality among females for the first time.
\end{abstract}

\section{Objectives}

The aim of the study was to analyze the traumatic deaths among females to determine the circumstances, causes and epidemiology of these deaths and also to find the factors influencing them.

\section{Methodology}

A retrospective descriptive study was conducted on the post mortem records of the female victims of trauma during last 3 years (2013-2015) reported to a tertiary care hospital of Sri Lanka. The historical details, scene findings, findings of autopsy: external and internal examinations, the results of the post-mortem investigations and the opinion and conclusions given were obtained to fill the pro-forma.

Key words: unnatural deaths, women, manner, road accidents, poisoning, family disputes

Corresponding author: indiradgk@yahoo.com

\section{Results}

Out of the 139 deaths reported for medicolegal examination during the period, the majority $71(51 \%)$ were less than 40 years of age. The commonest manner of death was accidents 56 (40\%), especially road accidents, followed by suicides amounting to $45(32 \%)$. Poisoning was the commonest method of suicide 14 (31\%) followed by hanging $12(26 \%)$. Sharp injuries accounted for the majority of murders 13 (39\%). Family disputes and love affairs were the main reason for $21(47 \%)$ suicides and 13 $(39 \%)$ murders.

\section{Conclusions}

Comprehensive research into occurrence of unnatural fatalities assists authorities in the prevention of such deaths. The study highlights the importance of timely interventions on road safety and the need for effective and timely counseling services on family matters to prevent most intentional deaths of women.

\section{INTRODUCTION}

An unnatural death is a death caused by external causes (injury or poisoning) which includes death due to intentional injury such as homicide or suicide, and death caused by unintentional injury in an accidental manner. ${ }^{1}$ An unnatural death can also be violent, mutilating or destructive. A sudden, accidental, unexpected or traumatic death of a female shatters the lives of the survivors or the family, especially, when their children are young. 
The extent of violence in the world has never been fully described. However, in 1996, the World Health Assembly identified violence as a leading global public health problem. ${ }^{2}$ Trauma is the third leading cause of death among all age groups and the mortality rate is remarkably high mainly among young age group. ${ }^{3}$ Although males are commonly the victims of traumatic deaths ${ }^{4}$, violence against women leading to traumatic deaths have been reported from many countries including India. ${ }^{5,6}$ The statistics and patterns of unnatural deaths vary in different countries. However, unintentional injury (largely motor vehicle accidents and poisoning) is the second leading cause of death among females less than 50 years of age. ${ }^{7}$ When considering motor vehicle accidents, the fatality rate is 3 folds higher among young males $(<25$ years of age) compared to young females. ${ }^{8}$ However, due to smaller body stature, female occupants were $28-31 \%$ more susceptible for fatal injuries than males from a similar crash of a motor vehicle. ${ }^{9} \quad$ Self-inflicted injuries as well as road injuries are among the top 10 causes of death of adult women (20-59 years) worldwide. $^{3,10}$ Burns are among the top 10 leading causes of death among women aged 15-44 years, especially in the South-East Asian region. ${ }^{10}$ Intimate partner and family violence as well as cooking accidents are responsible for considerably a higher amount of fire-related injuries as well as deaths among women ${ }^{10}$. Intimate partner violence is on the rise among females. ${ }^{10}$ Though the majority of victims of suicide are men, attempted suicide is more common among women. ${ }^{11}$ Traumatic injuries among females remain under-reported globally and studies on this area are scarce. ${ }^{12}$ We planned a retrospective descriptive study to find the epidemiologic patterns of trauma-related mortality among females since there is a scarcity of such literature.

\section{OBJECTIVES}

The aim of the study was to analyze the traumatic deaths among females to determine the circumstances, causes and epidemiology of these deaths and also to find the factors influencing them.

\section{METHODS}

A retrospective descriptive study was conducted on the post-mortem records of the female victims of trauma during the last 3 years reported to a tertiary care hospital of Sri Lanka. Women who are above 18 years of age were included in the study group. Autopsy reports, scene and post-mortem photographs and other case materials such as copies of the police scene investigation findings were perused. The historical details, scene findings, findings of autopsy external and internal examinations, the results of the post-mortem investigations and the opinions and conclusions given were obtained to fill the pro-forma.

Data collected were entered in Microsoft Excel worksheets and analysed using Statistical Package for Social Sciences (SPSS). Graphs and tables will be used as appropriate methods to present the data.

\section{RESULTS}

There were 139 women victims brought for medico-legal examination during the study period. The majority $71(51 \%)$ were less than 40 years of age. Most victims $112(81 \%)$ were married (Table:1).

Table 1: Age distribution

\begin{tabular}{|l|l|l|}
\hline Age groups & Frequency & Percentage \\
\hline$<20$ years & 19 & $14 \%$ \\
\hline 21-40 years & 52 & $37 \%$ \\
\hline 41-60 years & 40 & $29 \%$ \\
\hline$>60$ years & 28 & $20 \%$ \\
\hline Total & 139 & $100 \%$ \\
\hline
\end{tabular}


Table 2: Manner of death

$40 \%$ were accidental deaths while there were $32 \%$ suicides and $24 \%$ murders. There were $4 \%$ other deaths due to pregnancy and parturition-related issues (Table:2).

Among the accidental deaths, the majority $(64 \%)$ were road accidents while there were $16 \%$ burns (Table:3).

The method used to commit suicide was poisoning in a majority $(31 \%)$ while there were $27 \%$ of hanging incidents among the females who committed suicide (Table:3).

Majority (40\%) of the homicidal deaths were a result of sharp force injuries (Table:3).

\begin{tabular}{|l|l|l|}
\hline Manner & Frequency & Percentage \\
\hline Accidents & 56 & $40 \%$ \\
\hline Suicide & 45 & $32 \%$ \\
\hline Homicides & 33 & $24 \%$ \\
\hline Other (maternal) & 5 & $4 \%$ \\
\hline Total & 139 & $100 \%$ \\
\hline
\end{tabular}

Table 3: Method of unnatural death

\begin{tabular}{|l|l|l|}
\hline Type of accident & Frequency & Percentage \\
\hline Road & 36 & $64 \%$ \\
\hline Burn & 9 & $16 \%$ \\
\hline Fall & 3 & $5.3 . \%$ \\
\hline Railway & 3 & $5.3 \%$ \\
\hline Drowning & 2 & $4 \%$ \\
\hline Other & 3 & 5.3 \\
\hline Total & 56 & $100 \%$ \\
\hline
\end{tabular}

Type of suicide

\begin{tabular}{|l|l|l|}
\hline Method of suicide & Frequency & Percentage \\
\hline Poisoning & 14 & $31 \%$ \\
\hline Hanging & 12 & $27 \%$ \\
\hline Drowning & 8 & $18 \%$ \\
\hline Burn & 6 & $13 \%$ \\
\hline $\begin{array}{l}\text { Ligature } \\
\text { strangulation }\end{array}$ & 3 & $7 \%$ \\
\hline Train & 1 & $2 \%$ \\
\hline Other & 1 & $2 \%$ \\
\hline Total & 45 & $100 \%$ \\
\hline & & \\
\hline
\end{tabular}

Type of homicide

\begin{tabular}{|l|l|l|}
\hline Type of injury & Frequency & Percentage \\
\hline Sharp & 13 & $40 \%$ \\
\hline Blunt & 10 & $30 \%$ \\
\hline $\begin{array}{l}\text { Asphyxia including } \\
\text { drowning }\end{array}$ & 6 & $18 \%$ \\
\hline Burn & 4 & $12 \%$ \\
\hline Total & 33 & $100 \%$ \\
\hline
\end{tabular}


Cause of death in a majority 54 (39\%) was blunt force trauma which included multiple blunt force injuries, cranio cerebral trauma, shock and haemorrhage or chest trauma followed by neck compression in $17 \%$ (Table:4).

Alleged perpetrator in $30.5 \%$ of homicides was the husband while a similar percentage was inflicted by a known person to the victim (Table:5).

Most of the suicides (84\%) as well as homicides $(76 \%)$ had taken place at home (Table:6).

\section{Table 4: Cause of death}

\begin{tabular}{|l|l|l|}
\hline Cause of death & Frequency & Percentage \\
\hline Blunt force trauma & 54 & $39 \%$ \\
\hline Neck compression & 24 & $17 \%$ \\
\hline Burn and multi organ failure & 14 & $10 \%$ \\
\hline Poisoning & 14 & $10 \%$ \\
\hline Drowning & 12 & $9 \%$ \\
\hline Sharp force & 10 & $7 \%$ \\
\hline Sepsis & 2 & $1 \%$ \\
\hline Other & 9 & $7 \%$ \\
\hline Total & 139 & $100 \%$ \\
\hline
\end{tabular}

Table 5: Alleged perpetrator in homicides

\begin{tabular}{|l|l|l|}
\hline Alleged perpetrator & Frequency & Percentage \\
\hline Husband & 10 & $30.5 \%$ \\
\hline Known person & 10 & $30.5 \%$ \\
\hline Stranger & 4 & $12 \%$ \\
\hline Blood relative & 2 & $6 \%$ \\
\hline Other & 7 & $21 \%$ \\
\hline Total & 33 & $100 \%$ \\
\hline
\end{tabular}

Table 6: Location of the incident

\section{Suicides}

\begin{tabular}{|l|l|l|}
\hline Location & Frequency & Percentage \\
\hline Home & 38 & $84 \%$ \\
\hline Public & 4 & $9 \%$ \\
\hline Isolated place & 3 & $7 \%$ \\
\hline Total & 45 & $100 \%$ \\
\hline
\end{tabular}

\section{Homicides}

\begin{tabular}{|l|l|l|}
\hline Location & Frequency & Percentage \\
\hline Home & 25 & $76 \%$ \\
\hline Public & 1 & $3 \%$ \\
\hline Isolated place & 7 & $21 \%$ \\
\hline Total & 33 & $100 \%$ \\
\hline
\end{tabular}


Underlying reason for suicide as expressed by the relatives and the police was family dispute in a majority (36\%) while there were $22 \%$ where the reason was not known to the relatives (Table:7). Similarly, the underlying reason for homicide as expressed by the relatives and the police was family disputes in a majority (40\%) (Table:7).
Table7: Underlying reason for suicides and homicides

\begin{tabular}{|l|l|l|}
\hline Suicide & \multicolumn{2}{l|}{} \\
\hline Underlying reason & Frequency & Percentage \\
\hline Family dispute & 16 & $36 \%$ \\
\hline Love affairs & 5 & $11 \%$ \\
\hline Financial & 1 & $2 \%$ \\
\hline Not known & 10 & $22 \%$ \\
\hline Other & 13 & $29 \%$ \\
\hline Total & 45 & $100 \%$ \\
\hline Homicide & & \\
\hline Underlying reason & Frequency & Percentage \\
\hline Family dispute & 13 & $40 \%$ \\
\hline Love affairs & 0 & $0 \%$ \\
\hline Financial & 0 & $0 \%$ \\
\hline Not known & 12 & $36 \%$ \\
\hline Other & 8 & $24 \%$ \\
\hline Total & 33 & $100 \%$ \\
\hline
\end{tabular}

Out of the 45 suicides, the majority were young women. On the other hand, older victims were mainly victims of accidental deaths (Table:8).

Table 8: Age Vs. manner of death

\begin{tabular}{|l|l|l|l|l|l|l|l|l|}
\hline Age & Suicide & Accident & \multicolumn{3}{l|}{ Homicide } & \multicolumn{2}{l|}{ Other } \\
\cline { 2 - 9 } & Frequency & Percent & Frequency & Percent & Frequency & Percent & Frequency & Percent \\
\hline$<20$ & 9 & $20 \%$ & 6 & $11 \%$ & 4 & $12 \%$ & 0 & 0 \\
\hline $21-40$ & 24 & $53 \%$ & 16 & $28 \%$ & 10 & $30 \%$ & 2 & $40 \%$ \\
\hline $41-60$ & 9 & $20 \%$ & 15 & $27 \%$ & 13 & $40 \%$ & 3 & $60 \%$ \\
\hline$>60$ & 3 & $7 \%$ & 19 & $34 \%$ & 6 & $18 \%$ & 0 & $0 \%$ \\
\hline Total & 45 & $100 \%$ & 56 & $100 \%$ & 33 & $100 \%$ & 5 & $100 \%$ \\
\hline
\end{tabular}

Methods of suicide selected by young were hanging and poisoning, mainly. Older victims had selected drowning followed by poisoning to commit suicide (Table: 9).
Table 9: Method of suicide in each age group

\begin{tabular}{|l|l|l|l|l|}
\hline \multirow{2}{*}{ Method of suicide } & $<\mathbf{4 0}$ & $\mathbf{4 0}$ & \\
\cline { 2 - 5 } & Frequency & Percent & Frequency & Percent \\
\hline Poisoning & 10 & $30.5 \%$ & 4 & $33 \%$ \\
\hline Hanging & 10 & $30.5 \%$ & 2 & $17 \%$ \\
\hline Drowning & 3 & $9 \%$ & 5 & $42 \%$ \\
\hline Burn & 5 & $15 \%$ & 1 & $8 \%$ \\
\hline $\begin{array}{l}\text { Ligature } \\
\text { strangulation }\end{array}$ & 3 & $9 \%$ & 0 & $0 \%$ \\
\hline Train & 1 & $3 \%$ & 0 & $0 \%$ \\
\hline Other & 1 & $3 \%$ & 0 & $0 \%$ \\
\hline Total & 33 & $100 \%$ & 12 & $100 \%$ \\
\hline
\end{tabular}


Out of the 21 victims who died due to family disputes and broken love affairs, the majority $(58 \%)$ were less than 40 years of age (Table:10).

The reason for homicide among $42 \%$ of older victims was not revealed while family disputes were identified as the main reason for homicide among the young $(50 \%)$ (Table:10).

Table 10: reason for suicide and murder in each age group

\section{Suicide}

\begin{tabular}{|l|l|l|l|l|}
\hline \multirow{2}{*}{ Reason } & $\mathbf{4 0}$ & & $\mathbf{> 4 0}$ & \\
\cline { 2 - 5 } Love affair & Frequency & Percent & Frequency & Percent \\
\hline Family dispute & 14 & $15 \%$ & 0 & $0 \%$ \\
\hline $\begin{array}{l}\text { Financial or } \\
\text { other dispute }\end{array}$ & 0 & $43 \%$ & 2 & $17 \%$ \\
\hline Not known & 9 & $0 \%$ & 1 & $8 \%$ \\
\hline Other & 5 & $27 \%$ & 1 & $8 \%$ \\
\hline Total & 33 & $15 \%$ & 8 & $67 \%$ \\
\hline Morder & & $100 \%$ & 12 & $100 \%$ \\
\hline
\end{tabular}

Murder

\begin{tabular}{|l|l|l|l|l|}
\hline \multirow{2}{*}{ Reason } & $<\mathbf{4 0}$ & \multicolumn{2}{l|}{$\mathbf{~ 4 0}$} \\
\cline { 2 - 5 } & Frequency & Percent & Frequency & Percent \\
\hline Love affair & 0 & $0 \%$ & 0 & $0 \%$ \\
\hline $\begin{array}{l}\text { Family dispute } \\
\text { other dispute }\end{array}$ & 7 & $50 \%$ & 6 & $32 \%$ \\
\hline Not known & 0 & $0 \%$ & 0 & $0 \%$ \\
\hline Other & 4 & $29 \%$ & 8 & $42 \%$ \\
\hline Total & 3 & $21 \%$ & 5 & $26 \%$ \\
\hline & 14 & $100 \%$ & 19 & $100 \%$ \\
\hline
\end{tabular}

\section{DISCUSSION}

Unnatural deaths indicate the absence of social and mental wellbeing of a society. Especially when it comes to unnatural deaths of women, it can usually be attributed to their long-term deprivation of socio-economic and human rights, thereby reflecting a negative image of the society they belonged. Studying the profile of unnatural deaths is of extreme importance to a country, especially to draw policy in preventive strategies.

The study revealed that a majority $71(51 \%)$ were less than 40 years of age. This has been shown in many other studies, especially the ones done in neighboring India. ${ }^{13,14,15} 81 \%$ of them were married women, which again is consistent with other studies. ${ }^{13,16,17}$ The circumstances of unnatural deaths of females in our study showed that $40 \%$ were accidental deaths while there were $32 \%$ suicides and $24 \%$ murders. Similar patterns were also reported from various parts of India. ${ }^{18,19,20}$ However in Bangladesh, the commonest unnatural death of females is related to pregnancy and parturition ${ }^{21}$. Our study revealed only 5 deaths related to pregnancy. This indicates the quality of maternal health services in our country. The maternal mortality rate in Sri Lanka was 31 deaths/100,000 live births in year 2014, according to the World Bank.

Among the accidental deaths, the majority were road accidents (64\%) while there were $16 \%$ burns. High incidence of road traffic accidents among the females is a representation of the higher number of such accidents among the general population of Sri Lanka. Traffic accident in Sri Lanka shows an ever-increasing trend and an alarming number of fatalities are observed ${ }^{22}$. The total road fatalities for 2010 in Sri Lanka was 2854. Moreover, Sachi Kumar had reported road accidents as the number 1 accidental killer among females who are the victims of unnatural deaths in Lucknow, India. However, in his study, burns placed $3^{\text {rd }}$ accidental cause of death ${ }^{24}$. 
A review on traumatic injury among females by Ayman El-Menya et al had revealed that low and middle-income countries represent the majority of fatalities from burns. This includes both accidental, homicidal and suicidal burns. The review also shows that women and young children are at greater risk of domestic burns ${ }^{25}$. Further, many studies have also reported that female gender is at a high risk of death from burns ${ }^{26,27,28}$. This can be attributed to the use of firewood and kerosene oil used for cooking. The method used to commit suicide was poisoning in a majority $(31 \%)$ followed by hanging $(27 \%)$.

It is reported that females are likely to use a method that is not immediately lethal and, hence, poisoning or drug overdose is identified as the main method in other studies, too ${ }^{30,31}$.

However, the study also revealed that there is a significant number of immediately lethal other methods such as hanging, drowning and ligature strangulation used by our victims to commit suicide. In Europe, the most frequently practiced method of suicide among both genders was hanging; however, it was significantly higher in males than in females ${ }^{32}$.

The majority (40\%) of the homicidal deaths were a result of sharp force injuries. This is consistent with the trends of homicides in $\mathrm{UK}^{33}$. Sharp force injuries accounted for $22 \%$ of the homicidal deaths in Sri Lanka, when war- related fatalities were excluded ${ }^{34}$. However, in the United States firearm injuries are the commonest method of homicide followed by sharp force trauma ${ }^{35}$.

The cause of death in a majority (39\%) was blunt force trauma followed by neck compression. This contrasts with the studies done in India where burns are the commonest cause of death $^{6,19,36}$. However,

a study from Manipur had revealed a similar pattern to our study with a large number of road accidents accounting to blunt force trauma ${ }^{37}$.
Alleged perpetrator in $30.5 \%$ of homicides was the husband and there was another $30.5 \%$ in which the perpetrator was a known person to the victim. Intimate partner violence has been identified as a public health problem worldwide. Many women are killed by their husbands or intimate acquaintances $^{38}$. Women are rarely killed by strangers $^{33}$. This is commonly reported in Indian studies ${ }^{24}$. In 2007 intimate partners committed $14 \%$ of all homicides in U.S ${ }^{39}$.

Underlying reason for suicide as expressed by the relatives and the police was family disputes in a majority (36\%) while there were $22 \%$ of whom the reason was not known. On the other hand, the underlying reason for homicide as expressed by the relatives and the police was again the disputes in the family in a majority (40\%). A study into unnatural deaths of married females in India reveled that disputes with husband / in-laws and dowry-related problems were two important reasons behind suicidal as well as homicidal deaths ${ }^{40}$.

Among the suicides the majority (73\%) were young women. On the other hand, older victims were mainly victims of accidental deaths. Suicide rates are higher among females of 15-29 years of age worldwide ${ }^{41}$. It is well known that older adults or the elderly are the most at risk in pedestrian accidents. In Australia, about $2 \%$ of deaths of women aged 65 and over are attributed to non-traffic accidents ${ }^{42}$. Elderly victims have frail bodies and in addition, they have many natural disease conditions that can contribute to death from minor trauma.

Methods of suicide selected by the young were hanging and poisoning in equal numbers. Older victims of suicide had selected drowning to commit the act. A study done in Virginia revealed that the method of suicide changes with age, with more violent methods like firearm and hanging commonly being reported among the young ${ }^{43}$. Older females have commonly chosen drowning as the method of suicide as revealed in other studies as well ${ }^{44,45}$. 
Family disputes were the reason for both suicide and murder among the young. This is reported in other studies as well. Violence in families contributes highly to the pattern of homicides worldwide ${ }^{40,46}$.

\section{CONCLUSIONS}

Accurate, timely, and comprehensive research into occurrence of unnatural fatalities assists public health and other authorities in the development, implementation, and evaluation of programs and policies that reduce and prevent such deaths.

The study revealed that the unintentional trauma, mainly the road traffic accidents are responsible for unnatural deaths of females, in contrast to many studies from India where burns are responsible for the majority of such deaths. This highlights the importance of timely interventions of road safety measures. Further, women, especially the young are vulnerable for intentional unnatural deaths associated with family disputes, highlighting the importance of establishing freely/conveniently available counseling services.

\section{REFERENCES}

1. McGraw-Hill Concise Dictionary of Modern Medicine. (C) 2002 by The McGraw-Hill Companies, Inc

2. World Health Assembly. World Health Assembly resolution 49.25. Prevention of violence: a public health priority. Fortyninth World Health Assembly, Geneva, 25 May 1996.

3. Centers for Disease Control and Prevention (CDC). Web-based Injury Statistics Query and Reporting System (WISQARS) [Online]. (2013, 2011) National Center for Injury Prevention and Control,

4. Debra L. Karch, Joseph Logan, Dawn McDaniel, Sharyn Parks, Nimesh Patel, Surveillance for Violent Deaths - National Violent Death Reporting System, 16 States, 2009 Division of Violence Prevention, National Center for Injury Prevention and Control,
5. Tapse SP, Shetty, VB, Jinturkar AD. Medico-legal study of suspicious death in newly married females in Bidar, Karnataka,2012;6:130-2

6. Mayank Gupta, Awdhesh Kumar and Manoj Kumar Pathak, 2015."Pattern of unnatural death in females in Varanasi region- A retrospective study "International Journal of Current Research,7, (10), 21274-21276.

7. Leading Causes of Death Reports, National and Regional, 1999 - 2014 Centers for Disease Control and Prevention 1600 Clifton Rd. Atlanta, GA 30333, USA

8. Road traffic injuries, WHO Fact sheet N³58, March 2013. http://www.who.int/mediacentre/factsheets/f s358/en/, last access 24/03/2013.

9. World Health Organization: Gender and Road Traffic Injuries. 2002. http://www.who.int/gender/other_health/en/ gendertraffic.pdf. last access 24/03/2013

10. CDC (producer). Available from http://www.cdc.gov/injury/wisqars/index.ht $\mathrm{ml}$, Women's Health, Fact sheet. Geneva, World Health Organization, 2013. www.who.int/mediacentre/factsheets/fs334/ en/

11. Thompson, Martie; Laney S. Light (2011). "Examining Gender Differences in Risk Factors for Suicide Attempts Made 1 and 7 Years Later in a Nationally Representative Sample". Journal of Adolescent Health 48: 391-397. doi:10.1016/j.jadohealth.2010.07.018

12. Ayman El-Menyar, Hany El-Hennawy, Hassan Al-Thani, Mohammad Asim, Husham Abdelrahman, Ahmad Zarour, Ashok Parchani, Ruben Peralta and Rifat Latifi. Traumatic injury among females: does gender matter? Journal of Trauma Management \& Outcomes 2014, 8:8.http://www.traumamanagement.org/cont ent $/ 8 / 1 / 8$

13. Mandar Ramchandra Sane, Ananda K.Unnatural Deaths of Adult Females in South Bangalore An Autopsy Study. J

Indian Acad Forensic Med. April-June 2014, Vol. 36, No. 2: 131-132,

14. Pathak A and Sharma S.The Study of UnNatural Female Deaths in Vadodara City. J Indian Acad Forensic Med 2010; 32(3): 220223.

15. Kulshrestha P, Sharma RK, Dogra TD. The study of sociological and epidemiological variables of unnatural deaths among young women in south Delhi within seven years of 
marriage, J. Punjab Acad. For. Med. Toxicol 2002; 2: 717

16. Zine KU, Mugadlimath A, Gadge SJ, Kalokhe VS, Bhusale RG. Study of some socio-etiological aspects of unnatural female deaths at Government Medical College, Aurangabad. JIAFM 2009; 31(3): 210-217.

17. Dere RC and Rajoo KM.Study of Unnatural Deaths in Females, A Medico-legal Study at Rural Medical College, Loni. J Indian Acad Forensic Med. 2011; 33(3): 211-213.

18. Rajesh C. Dere Col. K.M. Rajoo. Study of Unnatural Deaths in Females A Medicolegal Study at Rural Medical College, Loni. J Indian Acad Forensic Med. July-September 2011, Vol.33, No. 3; 211-213,

19. CK Pawar, DS Bhullar,SS Oberoi, KK Aggarwal. Profile of Unnatural Deaths in Females A Retrospective Study. J Indian Acad Forensic Med. April-June 2014, Vol. 36, No. 2I;122-124,

20. Thounaojam Meera, Pabitramala Nandeibam, L Fimate, Saka Koko Maring, Mitul Sangma. Spectrum of unnatural female deaths in Manipur: A postmortem study $\mathbf{J}$ Med Soc 2015;29:88-91

21. Quamrun Nahar,Shams El Arifeen, Kanta Jamil and Peter Kim Streatfield. Causes of adult female deaths in Bangladesh:findings from two National Surveys. Nahar et al. BMC Public Health (2015) 15:911 DOI 10.1186/s12889-015-2256-6

22. A.K. Somasundaraswaran.Accident Statistics in Sri Lanka. IATSS RESEARCH 2006. Vol.30 No.1, 115-117

23. WHO, ed. (2013). "Global Status Report on Road Safety 2013: supporting a decade of action" (official report). Geneva, Switzerland: World Health Organisation (WHO). pp. vii, 1-8, 53ff (countries), 244251 (table A2), 296-303 (table A10). ISBN 978924156456 4. Retrieved 2014-0530. Tables A2 \& A10, data from 2010

24. Sachil Kumar, Anoop Kumar Verma, Wahid Ali, Abhishek. .A Study of Unnatural Female Death Profile in Lucknow, India. Am J Forensic Med Pathol 2013 Dec;34(4):352-6. doi: 10.1097/PAF.0000000000000053.

25. El-Menyar et al. Review Traumatic injury among females: does gender matter? Journal of Trauma Management \& Outcomes 2014, $8: 8$

26. Attia AF, Sherif AA, Mandil AM, Massoud MN, Abou-Nazel MW, Arafa MA:Epidemiological and sociocultural study of burn patients in Alexandria,Egypt. East Mediterr Health J 1997, 3(3):452-461.
27. Groohi B, Alaghehbandan R, Lari AR: Analysis of 1089 burn patients in province of Kurdistan. Iran Burns 2002, 28(6):569-574.

28. Estahbanati HK, Kashani PP, Ghanaatpisheh F: Frequency of Pseudomonas aeruginosa serotypes in burn wound infections and their resistance to antibiotics. Burns 2002, 28(4):340-348.

29. J.P.Bull, D.M.Jackson, Cynthia Walton. Causes and Prevention of Domestic Burning Accidents. Brit.Med.J.,1964,2,1421-1427

30. Schrijvers, Didier. "The gender paradox in suicidal behavior and its impact on the suicidal process". Journal of Affective Disorders $138 \quad$ (2): $19-26$. doi:10.1016/j.jad.2011.03.050

31. Sachil Kumar, Anoop K. Verma, Sandeep Bhattacharya, Shiuli Rathore. Trends in rates and methods of suicide in India. Egyptian Journal of Forensic Sciences.Volume 3, Issue 3, September 2013, Pages 75-80

32. Varnik, A; et al. "Suicide methods in Europe: a gender-specific analysis of countries participating in the European Alliance Against Depression". Journal of Epidemiology and Public Health 62 (6): 545-551. doi:10.1136/jech.2007.065391

33. Home Office / Office for National Statistics. Crime and Justic Chapter 2 Homicide:England and Wales:13 February 2014. www.ons.gov.uk

34. Edirisinghe PA and Kitulwatte ID. Extreme violence -homicide; an analysis of 265 cases from the offices of JMO Colombo and Ragama - a study from Sri Lanka.Leg Med (Tokyo) 2009; 11: S363-S365

35. Crime in the United States. Criminal Justice Information Services Division. FBI Expanded Homicide Data. https://www.fbi.gov/aboutus/cjis/.../expandhomicidemain

36. Numan Hussaini, Trishul Padole, Anil Batra, Anil Pinge, SK Hussaini. Profile of Unnatural Death of Adult Females in and

37. Around Akola - A Medico-Legal Study. J Cont Med A Dent January-April 2015 Volume 3 Issue 1. 58-61

38. Meera T, Nandeibam P, Fimate L, Maring SK, Sangma M. Spectrum of unnatural female deaths in Manipur: A postmortem study. J Med Soc 2015;29:88-91

39. Kellermann AL, Mercy JA. Men, women, and murder: gender-specific differences in rates of fatal Violence and victimization. $\mathbf{J}$ Trauma. 1992 Jul;33(1):1-5 
40. Shannan Catalano, Erica Smith, Howard Snyder, and Michael Rand. Female Victims of Violence. Bureau of Justice Statistics Selected Findings. U.S. Department of Justice Office of Justice Programs. September 2009, NCJ 228356

41. Rajesh Kumar Verma, P.C. Srivastava, U .S. Sinha, Archana Kau. Study of Unnatural Deaths in Married Females Within Seven Years of Marriage in Allahabad. J Indian Acad Forensic Med. October December 2015, Vol. 37, No. 4.;405-409

42. A Reza, J A Mercy, E Krug. Epidemiology of violent deaths in the world. Injury Prevention 2001;7:104-111

43. Whitlock FA, Boyce L, Siskind V Accidents in old age. Aust Fam Physician. 1978 Apr;7(4):389-99
44. Virginia Violent Death Reporting System (VVDRS), Office of the Chief Medical Examiner, Virginia Department of Health. Suicide Methods in Virginia: Patterns by Race, Gender, Age, and Birthplace (20032008). April, 2011

45. Avis SP. Suicidal drowning. J Forensic Sci. 1993 Nov;38(6):1422-6

46. Salib E, Agnew N. Suicide and undetermined death by drowning Int J Psychiatry Clin Pract. 2005;9(2):107-15. doi: 10.1080/13651500510018257

47. Meel B.L. Suicide among teenagers and young adults in the Transkei. Case reports. Anil Aggrawal's Internet Journal of Forensic Medicine and Toxicology, 2004; Vol. 5, No. 2, (July - December 2004):

http://anilaggrawal.com/ij/vol_005_no_002/ papers/paper003.html; (Accessed: January 09, 2016). 